\title{
Cyber-Sustainability: leaving a lasting legacy of human wellbeing
}

\author{
Bran Richards \\ Lancaster University \\ Lancaster, UK \\ b.richards@lancaster.ac.uk
}

\author{
Stuart Walker \\ Lancaster University \\ Lancaster, UK \\ s.walker@lancaster.ac.uk
}

\author{
Lynne Blair \\ Lancaster University \\ Lancaster, UK \\ Ib@comp.lancs.ac.uk
}

\begin{abstract}
This paper presents a case for the importance of sustainability in $\mathrm{HCl}$ as it relates to the Web. So far, the discussion about sustainability in $\mathrm{HCl}$ has focused on environmental aspects. However, our belief is that cyber-sustainability is much greater than this. We argue that to address cybersustainability correctly, the principles of sustainability should be considered in relation to 3 concerns: 1) environmental impacts, 2) psychological impacts, and 3) the worldview that the Web tends to promote. Several broad implications for more sustainable Web development are proposed.
\end{abstract}

Keywords: Sustainability, design, cyberspace, environment, wellbeing, worldview.

\section{INTRODUCTION}

Sustainability is a familiar term in the design community as it relates to material objects and their consumption, yet we rarely question the sustainability of our virtual environments. The fault may lie in the misconception of cyberspace as being infinite. In practice, cyberspace is constrained by server capacity, i.e. physical hardware, which has real life environmental implications (such as power consumption). But an underappreciated threat to the sustainability of our digital worlds is the unintended negative consequences they may be having on human wellbeing, and whether we as a species are able to survive its encroachment in our lives.

This paper argues that the issue of cybersustainability goes beyond our virtual worlds, because our engagement with technology shapes our worldview by reinforcing certain values and encouraging specific types of behaviour. The key contribution of Design for Sustainability (Walker, 2006) research is that achieving true sustainability requires a fundamental shift in our thinking and in the structure of our society. This paper proposes that part of the cyber-sustainability discussion needs to address the question of whether our virtual encounters are contributing to, or obstructing, the development of a worldview that will promote a healthier relationship to our physical environment.

The purpose of this paper is to contribute to the debate about the longterm viability of our current development paradigm and what kind of legacy we wish to leave for humankind. It is organized as follows.

We begin by exploring the often ignored environmental impact of our Web technologies, and discuss the direction these trends are heading with Web 3.0. We next discuss a small number of unintended consequences of the Web on our human wellbeing, which will only worsen if we do not make attempts to deliberately steer the course of Web design and development. Then we discuss the secondary implications of our Web engagements in fostering a worldview that perpetuates the negative trends identified in earlier sections. Finally, we propose some guidelines for more sustainable Web development, in order to leave a positive, lasting legacy.

\section{HIDDEN ENVIRONMENTAL IMPACT}

In 2008, Microsoft Research identified digital footprints as one of the issues facing $\mathrm{HCl}$ in the coming future (Harper et al., 2008). We tend not to think of the environmental cost of data storage, particularly because these costs have not yet translated into direct monetary terms for the ordinary consumer. For all intents and purposes, we see data as free, both economically and environmentally. The consequences of this perception are significant. Every month, 2.5 billion photos are uploaded to Facebook (Pingdom, 2010); every minute, 24 hours of video are uploaded to 
YouTube (YouTube, 2011); and the blogosphere doubles every 6 and a half months (Dube, 2006).

Of course the reason we are unconscious of the environmental impact of the Web is because, in the name of usability, we aim to conceal its means and present it to the user as an unmediated experience (Borgmann, 1984). We have created the illusion of interaction in an immaterial space, which, if it were true, would mean this activity could not possibly have real world environmental costs. However, nothing is as free as it appears in cyberspace. When using the Web our browser's computer consumes electricity, estimated between 12 and $150 \mathrm{~g}$ of greenhouse gasses $\left(\mathrm{CO}_{2} \mathrm{e}\right)$ per hour (Berners-Lee, 2010). (For comparison, boiling a litre of water using an electric kettle consumes $70 \mathrm{~g}$ $\mathrm{CO}_{2} \mathrm{e}$.) In 2008, the Web itself represented $5 \%$ of the world's total global electricity usage and it is continuing to rise (Kelly, 2007). We also use servers and networks to the tune of $50 \mathrm{~g} \mathrm{CO}_{2} \mathrm{e}$ per hour as of 2010 and this is also rising. We rely on data centres, which emit 130 million tonnes $\mathrm{CO}_{2} \mathrm{e}$ globally per year today, but are estimated to emit 250-340 million tonnes $\mathrm{CO}_{2} \mathrm{e}$ per year by 2020 (Berners-Lee, 2010). Additionally, we need technologies to enable us to access and interact with the Web. Mobile phones, eReaders, and computers, all consume virgin materials, emit $\mathrm{CO}_{2} \mathrm{e}$ during their production and use, and contribute to eWaste (Grossman, 2006).

The real danger comes when these consumption trends continue to accelerate unabated, and indeed are glorified by the proponents of Web 3.0 who dream that cyberspace will eventually hold everything imaginable (Berners-Lee, 2009; Kelly, 2007). It might be argued that these 'visionaries' suffer from a form of ecstatic myopia, failing to recognize that as we become increasingly dependent on cyberspace as storage for all we value, we are forever consigning ourselves to supplying energy to maintain it, unable to disengage when the environment inevitably compels us to do so.

Our mass migration into cyberspace has often been compared to the Gold Rush; except many contend that the difference is that in cyberspace, the resources will never dry up (Bezos, 2003). Yet even if the rate of our improvement of digital capabilities continues to outpace our production of data, the cost of upgrading our hardware to keep up with our storage requirements will be unmanageable quantities of eWaste. But perhaps more insidiously, and as we shall see in the next section, we are inadvertently enabling an irresponsible production and consumption of data, which contributes to the proliferation of an unsustainable worldview that may have knock-on effects in terms of our relation to our physical environment.

\section{PSYCHOLOGICAL IMPACTS}

There is a growing awareness of the environmental aspects of sustainability in $\mathrm{HCl}$ (DiSalvo et al., 2010; Huang et al., 2009; Nathan et al., 2008; Blevis, 2007; Mankoff et al., 2007), but thus far the human aspects of sustainability have largely been ignored. In the following section, we will explore the potentially unsustainable psychological impacts of the Web as it exists now.

\subsection{Damage to wellbeing}

Mental health statistics reveal a disturbing trend: today's "average (i.e., normal) young person... scores as high on anxiety scales as children who were admitted to clinics for psychiatric disorders in $1957 ", 21 \%$ of them at least minimally impaired by a mental or addictive disorder (Schor, 2004). Schor blames consumerism for these shocking figures, in part because a culture of 'getting' contributes to feelings of inadequacy for those who cannot have what others have. What we see in our use of Web 2.0 is that feelings of inadequacy frequently spring from our inability to keep up with the constant stream of information available for consumption. Trying to reach the end is like trying to chase down a photon. And while we know it is impossible, we are encouraged to follow this will-o-the-wisp by developing tools that enhance our informationgathering capabilities. The resulting psychological disorder is our insatiable desire for information what we refer to here as information pleonexia.

A new study by Retrevo Gadgetology reports that nearly half of respondents indicated that they check their social media (e.g. Facebook, Twitter, etc.) during the night or as soon as they wake up, which is suggestive of addiction (Elsner, 2010). There can be devastating social impacts of this addiction to information, not just in terms of the amount of time it takes away from our real-world relationships, but because it can reduce our capability to be compassionate, empathetic, and tolerant (Naish, 2009). Research indicates that we are so overloaded with information that our mental abilities cannot keep up, meaning that not only do we struggle to make intellectual sense of this information, but we cannot possibly make emotional sense of it either.

We have seen above how unbridled consumption can negatively impact mental health. Other psychologists (Christopher \& Schlenker, 2004; Kasser, 2002) explain our culture's soaring rates of anxiety and depression as being a result of the promotion of materialistic values, the nuance being that materialism is extrinsically motivated. 
Materialistic individuals seek external rewards and are overly concerned with how people perceive them (Christopher \& Schlenker, 2004). And despite existing in a non-material space, social media seems to be exacerbating materialism, as adolescents and adults alike fall into the trap of measuring their self-worth by their Facebook traffic. Contributing to this is the fundamental mistake that Facebook and other social networks make, namely that online 'friendships' are founded in information sharing, and the quality of these 'friendships' is measured by the rate of flow of that information. Jaron Lanier (Lanier, 2010) suggests that this abstraction is leading to a devaluation of the very notion of friendship, chipping away at one of our most important sources of meaning.

While supposedly 'connecting' and 'informing' us, our virtual engagements seem to be promoting addictive behaviour and eroding attention, emotional capacity, a sense of coherence, and substantive notions of meaning. The question we have to ask is how much more our mental health can withstand, and whether we will eventually reach the point that our only resort is disengagement from cyberspace.

\subsection{Reaching a breaking point}

A 2005 study (Niemz et al., 2005) revealed a disturbing growth of Internet addiction, estimated to be as high as $18 \%$ of British students. Support groups abound for this new disorder. And yet certain Web 3.0 enthusiasts embrace the inevitability of the final "McLuhan Reversal", where the human becomes an extension of the machine; in other words, a state where we are entirely dependent on technology (Kelly, 2007). This scenario can only exacerbate unhealthy addictions and our anxiety at the notion of being separated from the Web.

Meanwhile many others who may not fall under the category of the clinically addicted are seeking to free themselves from the grip of social media (e.g. Web 2.0 Suicide Machine, http://suicidemachine. org/ - a web-based service that will eradicate all one's social media information and which promotes itself with the tag line, 'Wanna meet your real neighbours again?'). And yet our most celebrated Web 'visionaries' are demanding more data (Berners-Lee, 2009), indicating we are in a positive feedback loop for information pleonexia - both for users and developers of the Web. Furthermore, the call of Web 3.0 is for unfiltered data: anything and everything is to be added to our already disappointing "mediocre mush" (TheGuardian, 2010). At this rate, the ecosystem of cyberspace will become inhabitable. We will not be able to see the information we seek through the smog of data, and we will feel increasingly choked by its toxic atmosphere.
For many, the Web 2.0 hype fails to deliver. We see examples emerging like Path, the alternative to Facebook, which aims to encourage more meaningful and fulfilling friendship connections by capping networks (Levy, 2010). It seems that there are some initial indications that our enthusiasm for Web 2.0 is beginning to wane. For example, while Second Life can boast of continued 'growth' in its user base, the number of users logged in simultaneously is in decline (Wagner, 2010); and $73 \%$ of Twitter's users have tweeted less than 10 times (Parr, 2010).

Perhaps the message we should be taking from this is that the Web needs to be more ambitious in its aims, rather than in its scope. What our wellbeing demands is less information, but greater meaning. While the Semantic Web is beginning to address how we find information that is meaningful for our search purposes, what we also must consider is other dimensions of human meaning that we can begin to incorporate into the very foundation of the Web.

\subsection{Creating a worldview}

The Web also affects our psychology in subtler ways, by influencing the development of our worldview, i.e. our orientation to the world and our understanding of our role in it. Without implying any conscious or sinister motivations, we suggest that the Web produces a kind of intelligibility that works to promote a worldview that is at odds with sustainable living. So while it would be difficult to prove, it seems likely that participating in an accelerated and risk-free cycle of production, consumption and waste in cyberspace reinforces these bad habits in the physical world; whereas a sustainable future would require our cultivation of responsible stewardship.

The web tends to condition us to expect immediacy and ease. In doing so, it spoils us, making it more difficult to recognise or respond to the fact that we may soon have to take a very different path if we are to survive as a species. This is not a question of 'greening' our practices (e.g. Zelman, 2011). In fact, making our irresponsible behaviour less damaging to the environment only further reinforces the fundamentally unsustainable notion that we can retain our highly consumptive lifestyles so long as we make minor adjustments. What is clear from Design for Sustainability research is that true sustainability will not be reached without people accepting drastic changes to their current way of life (Jackson, 2009; Walker, 2006; Davison, 2001; Daly, 1997).

Unfortunately, what we see is that the current unsustainable models persist because they are highly integrated (economically, socially, culturally, 
and philosophically) and are thus mutually reinforcing and self-perpetuating. In other words, the reason we live unsustainably is because it makes a certain sense to us, therefore what is required most of all is a radical shift in our thinking.

But perhaps our greatest hope for a more harmonious relationship with our environment lies in the fact that our interactions with technology influence our understanding of our world and our role in it (Borgmann, 1984); as such technology is our most powerful tool for affecting a more sustainable worldview. If we aim to design the Web upon a foundation informed by principles of sustainability, our engagements in cyberspace must begin to foster behaviour conducive to human and planetary wellbeing.

\section{POSSIBLE DIRECTIONS FORWARD}

If, as we propose, our current approach to development in cyberspace is unsustainable from both an environmental and psychological perspective, it is only a matter of time before we are forced to make changes that will likely be highly disruptive to our way of living. Yet if we begin to formulate a desirable alternative now, we may be able to embrace these necessary changes as opportunities to create something better than the Web as we know it today.

One of the clear imperatives is to curb our (seemingly) mindless expansion of the Web, though we anticipate objections to any discussion of restrictions, given the Web's supposedly democratic foundation. But we must recognize that if the cost of greater and less contextualized information (i.e. raw data) means that fewer people find any meaningful coherence in cyberspace, we are unintentionally producing an elite class of those who can interpret and disseminate their knowledge to the masses. In other words, we should shake ourselves free of the notion that more information is the same as greater democracy. Furthermore, democracy is about more than freedom of action and information. As Lanier explains, "it's the thing that... allows us to act better than we otherwise would" (TheGuardian, 2010). We see glimmers of this potential with the stirrings of a grassroots movement working to secure social justice and environmental harmony (Hawken, 2004), but for the most part, the Web has failed to realize this massive potential.

Indeed the most significant shift may be in constructing a new purpose for cyberspace. Although initially borne out of practical needs for governmental and institutional information exchange, this foundation may not be meaningful enough now that we have appropriated the Web for social purposes. Rather than serving to merely augment our cognitive abilities, we ought to be aiming to design the Web so that it supports our holistic, human development.

It is worth reflecting on whether the current values underpinning Web development are truly our human aspirations. We may benefit from adopting principles of the Slow Movement (Footprint Choices, 2011), which encourages people to reprioritize and make a considered effort to foster connections to people, place, and the things we consume.

The table below summarizes some key considerations for the development of a more sustainable cyberspace.

Table 1: Proposed directions for $\mathrm{HCl}$ for the Web

\begin{tabular}{|c|c|c|}
\hline HCI & Current & Future \\
\hline Externalities & hidden & reflected \\
\hline \multirow{10}{*}{ Values } & wants & needs \\
\hline & having & being \\
\hline & information & wisdom \\
\hline & volume & meaning \\
\hline & growth & moderation \\
\hline & speed & consideration \\
\hline & ease & fulfillment \\
\hline & breadth & depth \\
\hline & freedom & democracy \\
\hline & augmentation & $\begin{array}{c}\text { holistic } \\
\text { devevlopment }\end{array}$ \\
\hline \multirow{4}{*}{$\begin{array}{c}\text { Supported } \\
\text { Engagements }\end{array}$} & connection & communication \\
\hline & consumption & care \\
\hline & disposability & responsibility \\
\hline & mindlessness & reverence \\
\hline Relationship & co-dependence & independence \\
\hline
\end{tabular}

Traditional notions of the sustainability of our material production include economic, environmental, and social factors. This model, also known as the triple bottom line of sustainability, fails to account for the human on the individual level, and only recently has the design community begun to recognise the need for a fourth bottom line, such as personal meaning (Walker, 2011). Learning from this example, we suggest that cybersustainability would benefit from considering the individual human impacts of the Web up front. Even the environmental, economic, and social impacts of the Web - what we call its externalities - can be viewed from this individual human perspective, if we consider the degree to which these impacts are hidden from or accessible to people. So rather than concealing these externalities, a more sustainable alternative would be to expose them, or perhaps reflect them in cyberspace development (e.g. in costs). Along these same lines, we must address the values embodied by, and subtly communicated to us by the Web, as well as the engagements it supports, all of which contribute to the development 
of our worldview and our notions of appropriate behaviour.

Simply put, we would do well to cultivate a greater reverence for cyberspace, lest we waste, abuse, or take for granted the opportunity it affords for humanity. This does not, however, imply we ought to idolize this technology. Rather we should seek greater independence from it, not merely because we may one day have to reduce our technological consumption to live more sustainably, but also because our human wellbeing demands we assert our control over the technologies and work to reduce the impact of their unintended harmful consequences.

\section{CONCLUSIONS}

We have proposed a threefold framework for cybersustainability that considers 1) the real world environmental impact of our Web technologies, 2) their impact on human wellbeing, and 3) the ways in which they shape our worldview - contributing to our notions of meaning, encouraging certain behaviours, and affecting our relationship to our planet. Our proposed possibilities for new $\mathrm{HCl}$ for the Web are just the starting point of what we hope will become an ongoing discussion about the greater potential to be found in cyberspace, that may not only bring us closer to environmental and human harmony, but may unlock unimagined human greatness.

It seems sensible to ask whether or not cybersustainability is even possible. We could equally ask that of Design for Sustainability in general; but to do so is to underestimate the value of having an ideal to strive for. Sustainability has in many ways become our contemporary mythology, embodying our very real fears that we cannot go on living the way we are now, and warning us that if we do not make major change we will be responsible for our own destruction (Walker, 2006). Similarly, cybersustainability strives for an ideal, without illusions that we will ever fully arrive at perfection. Nonetheless, it inspires us to be great, and to make the difficult design decisions that will leave a positive and lasting legacy that we can be proud of.

\section{REFERENCES}

Berners-Lee, M. (2010) How Bad Are Bananas. Profile Books Ltd., London.

Berners-Lee, T. (2009) Tim Berners-Lee on the next Web [video online]. http://www.ted.com/talks /tim_berners_lee_on_the_next_web.html February 2011).

Bezos, J. (2003) Jeff Bezos on the next web innovation [video online]. http://www.ted.com/ talks/jeff_bezos_on_the_next_web_innovation.html (13 February 2011).

Blevis, E. (2007) Sustainable Interaction Design: Invention \& Disposal, Renewal \& Reuse. In CHI '07 Proceedings of the SIGCHI conference on Human Factors in computing systems, San Jose, CA, 28 April - 3 May, pp. 503-512. ACM, New York.

Borgmann, A. (1984) Technology and the Character of Contemporary Life. The University of Chicago Press, Chicago.

Christopher, A.N. \& Schlenker, B.R. (2004) Materialism and affect: The role of selfpresentational concerns. Journal of Social and Clinical Psychology, 23(2), 260-272.

Daly, H. (1997) Beyond Growth. Beacon Press, Boston.

Davison, A. (2001) Technology and the Contested Meanings of Sustainability. State University of New York Press, Albany.

DiSalvo, C., Sengers, P. \& Brynjarsdóttir, H. (2010) Mapping the Landscape of Sustainable $\mathrm{HCl}$. In $\mathrm{CHI}$ ' 10 Proceedings of the $28^{\text {th }}$ international conference on Human factors in computing systems, Atlanta, GA, 10-15 April, pp. 1975-1984. ACM, New York.

Dube, J. (2006) How many blogs are there? 50 million and counting. CyberJournalist.Net. $7^{\text {th }}$ August 2006. http://www.cyberjournalist.net/news/ 003674.php (12 February 2011).

Elsner, A. (2010) Is Social Media a New Addiction? Retrevo Blog. $15^{\text {th }} \quad$ March 2010. http://www.retrevo.com/content/blog/2010/03/social -media-new-addiction\%3F (4 February 2011).

Footprint Choices (2011) The Slow Movement: Making a Connection. http://www.slowmovement. com/ (18 February 2011).

Grossman, E. (2006) High Tech Trash. Island Press, Washington.

Harper, R., Rodden, T., Rogers, Y. \& Sellen, A. (2008) Being Human. Microsoft Research Ltd., Cambridge.

Hawken, P. (2004) Blessed Unrest. Penguin books, New York.

Huang, E.M., Blevis, E., Mankoff, J., Nathan, L.P., \& Tomlinson, B. (2009) Defining the Role of $\mathrm{HCl}$ in the Challenges of Sustainability. In $\mathrm{CHI}$ '09 Proceedings of the $27^{\text {th }}$ international conference extended abstracts on Human factors in computing systems, Boston, MA, 4-9 April, pp. 4827-4830. ACM, New York.

Jackson, T. (2009) Prosperity without Growth. Earthscan, London.

Kasser, T. (2002) The High Price of Materialism. MIT Press, Cambridge.

Kelly, K. (2007) Kevin Kelly on the next 5,000 days of the web [video online]. http://www.ted.com/ talks/kevin_kelly_on_the_next_5_000_days_of_the _web.html (12 Fébruary 2011).

Lanier, J. (2010) You Are Not A Gadget. Allen Lane, London.

Levy, S. (2010) New social network limits you to 50 friends. Wired.co.uk. $15^{\text {th }}$ November 2010. 
http://www.wired.co.uk/news/archive/201011/15/pat h-social-network (22 January 2011).

Mankoff, J.C., Blevis, E., Borning, A., Friedman, B., Fussell, S.R., Hasbrouck, J., Woodruff, A. \& Sengers, P. (2007) Environmental Sustainability and Interaction. In $\mathrm{CHI}$ '07 extended abstracts on Human factors in computing systems, San Jose, CA, 28 April - 3 May, pp. 2121-2124. ACM, New York.

Naish, J. (2009) Warning: brain overload. The Times. $2^{\text {nd }}$ June 2009. http://women.timesonline. co.uk/tol/life_and_style/women/the_way_we_live/ar ticle6409208.ece (2 February 2011).

Nathan, L.P., Blevis, E., Friedman, B., Hasbrouck, J. \& Sengers, P. (2008) Beyond the Hype: Sustainability \& $\mathrm{HCl}$. In $\mathrm{CHI}$ '08 extended abstracts on Human factors in computing systems, Florence, 5-10 April, pp.2273-2276. ACM, New York.

Niemz, K., Griffiths, M. \& Banyard, P. (2005) Prevalence of Pathological Internet Use among University Students and Correlations with SelfEsteem, the General Health Questionnaire (GHQ), and Disinhibition. CyberPsychology \& Behavior, 8(6), 562-570.

Parr, B. (2010) The Truth About the Average Twitter User [STATS]. Mashable. 10 ${ }^{\text {th }}$ March 2010. http://mashable.com/2010/03/10/twitter-follow-stats/ (15 February 2011).

Pingdom (2010) Internet 2009 in numbers. Royal Pingdom. $22^{\text {nd }} \quad$ January 2010. http://royal.pingdom.com/2010/01/22/internet-2009in-numbers/ (9 February 2011).

Schor, J.B. (2004) Born To Buy. Scribner, New York.

TheGuardian (2010) Jaron Lanier talks about the failure of Web2.0 with Aleks Krotoski [video online]. http://www.youtube.com/watch?v=alwik I7IVYs (17 February 2011).

Wagner, M. (2010) Second Life CEO looks to the future, after massive layoffs. Computerworld. $10^{\text {th }}$ June 2010. http://blogs.computerworld.com/ 16303/second_life_layoffs (15 February 2011).

Walker, S. (2011) The Spirit of Design. (In Press, due 06/11) Earthscan/James \& James Scientific Publishers, London.

Walker, S. (2006) Sustainable By Design. Earthscan, London.

YouTube (2011) YouTube Fact Sheet. http://www.youtube.com/t/fact_sheet (9 February 2011).

Zelman, J. (2011) Transphorm, Google-Backed Startup, Claims Major Breakthrough In Energy Technology. The Huffington Post. $25^{\text {th }}$ February 2011. http://www. huffingtonpost.com/2011/02/25/ transphorm-google_n_828427.html (25 February 2011). 